\title{
Breastfeeding practices among slum mothers: a multivariate statistical analysis
}

\author{
Rafiqul Ia, Mahfuzar Ra, Mosfequr Ra, Nazrul IM ${ }^{\mathrm{a}}$ \\ aDepartment of Population Science and Human Resource Development, University of Rajshahi, Rajshahi-6205, \\ Bangladesh.
}

\begin{abstract}
Introduction: The aim of this study was to determine the differential patterns of mean duration of breastfeeding among mothers from slum areas in Rajshahi City, Bangladesh by using the multiple classification analysis (MCA). Materials and Methods: The data for this study was collected from mothers from slum areas of 8 different slums of Rajshahi City Corporation who had had at least one child at the time of interview. Results: We showed that the overall mean duration of breastfeeding was $\mathbf{2 4 . 6 6}$ months for all women, which may show considerable impact on fertility around slum areas in near future. Conclusion: Of all the selected variables in MCA, it was seen that the current age of the children and the body mass index of the respondents appear as the strongest important determinants of duration of breastfeeding and other variables play relatively less important role on the duration of breastfeeding.
\end{abstract}

KEY WORDS: Breastfeeding, Slum mothers, Body mass index (BMI) and Multiple Classification Analysis (MCA).

\section{INTRODUCTION}

Breastfeeding is the feeding of an infant or young child with milk from breasts of a woman. Babies have a sucking reflex that enables them to suck and swallow milk. Human breast milk is the best source of nourishment for human infants. ${ }^{1}$ Feeding practices play a pivotal role in determining the optimum development of infants and children because it is an unequalled way of providing ideal food for their healthy growth and development. It is also an integral part of the reproductive process with important implications for the health of the mothers.

Breastfeeding is almost universal in Bangladesh. About $98 \%$ of children are breastfed at some point and overall, $24 \%$ of children are breastfed within one hour of birth, and $83 \%$ are breastfed within one day after delivery. ${ }^{2}$ Human milk is the preferred feeding for all infants, including premature and sick newborns, with rare expectations. ${ }^{3}$ The benefits for the children include improved digestion and absorption of nutrients, gastrointestinal function, neurodevelopment, host defenses and maternal psychological wellness. ${ }^{4,5}$ Breastfeeding is the best and safest way of feeding infants for the first 4-6 months of life. It provides the perfect nutrition for infants and lays the foundation for their healthy psychological development. ${ }^{6}$ Besides, it also immunizes the child against common infections. ${ }^{7}$ In countries with moderate or high infant mortality rate, artificially fed infants are at least 14 times more likely to die from pneumonia. ${ }^{8}$ In communities with high prevalence of malnutrition, breastfeeding may substantially enhance survival of children up to three years of age. ${ }^{9}$ In addition to its direct nutritional value for infants and young children, breastfeeding contributes by reducing the risk of the mothers developing breast cancer.8 Lactational anovulation, associated with amenorrhoea resulting from exclusive breastfeeding, represents an important child-spacing mechanism. ${ }^{10}$ Breast milk is the natural first food for babies. It promotes sensory and cognitive development, and also protects infants against infectious and chronic diseases. Women and children living in slum areas are the most vulnerable group with inadequate services of water supply, sanitation, good health care etc. About $75 \%$ of the 12 million deaths among children who are under five years of age is due to curable diseases, such as pneumonia, diarrhea, measles, malaria or malnutrition. ${ }^{11}$ Exclusive breastfeeding reduces infant mortality due to common childhood illnesses such as diarrhoea or pneumonia, and helps for a quicker recovery during illness. ${ }^{12}$

Internationally, breastfeeding has received increased attention as a focus for improving public health. Breastfeeding has increasingly been recognized as the optimal form of infant feeding. ${ }^{13}$ Research has provided evidence that breastfeeding increases a baby's resistance to infection and disease and is particularly suited to the growth and requirements of the infant. ${ }^{14}$ Breastfeeding also helps to delay the resumption of ovulation and thus promotes spacing of births. Thus it is necessary to investigate how long mothers in slum areas of RCC breastfed their babies, and the impact of this activity on fertility.

Therefore, the specific aim and objective of this study is to examine the contribution of some selected variables (age of children, BMI respondents, living children, usage of family planning, current age of 


\section{MATERIALS AND METHODS}

The data for this study was collected from 1st of July to 29th July 2006, from 8 different slums of 3 wards of RCC, Bangladesh. Seven hundred married women aged 15-49 years were selected using purposive sampling technique and were successfully interviewed through personal interview. Women who had no children below five years of age at the time of the interview were not included. Details of the 700 respondents is as shown in Table I.

Table I . List of selected slum areas and sample size used in this study

\begin{tabular}{|c|c|c|c|}
\hline Name of Slum & $\begin{array}{l}\text { Ward } \\
\text { No. }\end{array}$ & $\begin{array}{c}\text { Slum } \\
\text { Population }\end{array}$ & $\begin{array}{l}\text { Sample } \\
\text { Size }\end{array}$ \\
\hline $\begin{array}{l}\text { Dharompur } \\
\text { Nadirdhar }\end{array}$ & 28 & 7260 & 300 \\
\hline \multicolumn{4}{|l|}{$\begin{array}{l}\text { Char Kazla } \\
\text { Badurtola }\end{array}$} \\
\hline $\begin{array}{l}\text { Dashmari } \\
\text { Nadirdhar }\end{array}$ & 29 & 7235 & 300 \\
\hline \multicolumn{4}{|l|}{$\begin{array}{l}\text { Khozapur } \\
\text { Nadirdhar }\end{array}$} \\
\hline \multicolumn{4}{|l|}{$\begin{array}{l}\text { Satbaria } \\
\text { Nadirdhar }\end{array}$} \\
\hline \multicolumn{4}{|l|}{$\begin{array}{l}\text { Shympur } \\
\text { Nadirdhar }\end{array}$} \\
\hline $\begin{array}{l}\text { Paschim Para } \\
\text { Boodh Para }\end{array}$ & 30 & 2135 & 100 \\
\hline \multicolumn{4}{|l|}{ Mohonpur } \\
\hline Total & & 700 & \\
\hline
\end{tabular}

Multiple classification analysis (MCA) is a technique that can handle predictors with no better than nominal measurements and interrelationships of any form among the predictor variables or between a predictor and dependent variable. Therefore, to examine the differential patterns of duration of breastfeeding by a set of socio-economic and demographic factors MCA is employed using computer software SPSS 7.5 version. It is however essential that the dependent variable should be either an interval-scale variable without extreme skewedness or a dichotomous variable with frequencies which are not extremely unequal.

The MCA technique developed by Yates and it was later expanded and detailed by Anderson and Bancraft. ${ }^{15,16}$ The computerized MCA program was prepared by a group of researchers at the survey research center of the University of Michigan. ${ }^{17}$ Since then, the MCA program has been widely used in social research. In statistical terms, the MCA model specifies that a coefficient be assigned to each category of each predictor, and that each individual's score on the dependent variable be treated as the sum of the coefficients assigned to categories characterizing that individual respondents, their education and problem during last pregnancy) on breastfeeding practices among slum mothers. These variables are selected for the analysis because it is to believe that breastfeeding practices are closely related to those variables.

plus the average for all cases, plus an error term. In fact, MCA is a method for doing linear regression with categorical variables.

$$
\mathrm{Y}_{i j k}=\overline{\mathrm{Y}}+a_{i}+b_{i}+c_{k}+\ldots \ldots \ldots \ldots \ldots+e_{i j k}
$$

where,

$\mathrm{Y}_{i j k}=$ The value or score of an individual who falls in the ith category of the factor $A$, jth category of the factor $B$ and kth category of the factor $C$.

\section{$\overline{\mathrm{Y}}=$ Grand mean of}

$a_{i}=$ The effect due to the ith category of the factor $A$, which is equal to the difference between and the mean of its category of factor A.

$b_{j}=$ The effect due to the jth category of the factor $B$, which is equal to the difference between and the mean of its category of factor $B$.

$c_{k}=$ The effect due to the kth category of the factor $C$, which is equal to the difference between and the mean of its category of factor $C$.

$e_{i j k}=$ The error term related with score of the individuals.

There are two effects in MCA- gross/unadjusted effect and net/adjusted effect. These effects measure those of the predictor alone after taking into account the effects of all other predictors. The unadjusted, etasquare $\left(\mathrm{h}^{2}\right)$ coefficients are correlation ratio, which explain how well the predictor variable explains the variation in the dependent variables. Similarly, the beta-square $\left(b^{2}\right)$ coefficient indicates the proportion of variation explained by the other predictor variables.

\section{Variables considered in the analysis}

The MCA is undertaken to evaluate the contribution of such factors as the current age of children, body mass index (BMI) of the respondents, number of living children, currently using FP, current age of respondents, educational level of respondents and problems during last pregnancy on duration of breastfeeding. In this case, the duration of breastfeeding is taken to be the dependent variable and the aforesaid variables are to be the explanatory variables. All the variables are included in MCA in the following fashion:

\section{Duration of breastfeeding: single month}

Children's current age: $0=\leq 3$ years, $1=3+$ years

BMI of the respondents: $0=<18.5,1=18.5-24.9,2=25+$

Number of living children: $0=1,1=2+$ 
Currently using Family planning: $0=$ No, $1=$ Yes

Current age of respondents: $0=>20,1=20-29,2=30-49$ Education level of respondents: $0=$ Illiterate, $1=$ Primary, 2=Secondary+ Problem during last pregnancy: $0=$ No, $1=$ Yes.

\section{RESULTS AND DISCUSSION}

\section{Background Characteristics}

Table II shows the background characteristics of the respondents. Results showed that about $70 \%$ of the children in the study are in the age group years. More than $70 \%$ of the respondents had normal BMI whereas about $10 \%$ of them had BMI of $<18.5$. About $60 \%$ of the respondents had 2 or more living children. A very high percentage (98\%) of the respondents used family planning. For the factor of current age, $25 \%$ of the respondents were in the age group $<20$ years, and more than 55\% were in the age group 20-29 years. About $50 \%$ of the respondents were illiterate.

Table II. Respondents by background characteristics

\begin{tabular}{|c|c|c|}
\hline Background characteristics & $\begin{array}{l}\text { Number of } \\
\text { respondents }\end{array}$ & $\begin{array}{c}\text { Percentage } \\
\text { (\%) }\end{array}$ \\
\hline \multicolumn{3}{|l|}{ Children's age } \\
\hline$\leq 3$ years & 480 & 68.6 \\
\hline $3>$ years & 220 & 31.4 \\
\hline \multicolumn{3}{|l|}{ Respondent's BMI } \\
\hline$<18.5$ (thin) & 68 & 9.7 \\
\hline 18.5-24.9 (normal) & 505 & 72.2 \\
\hline$\geq 25$ & 127 & 18.1 \\
\hline \multicolumn{3}{|l|}{ (over-weight/obese) } \\
\hline \multicolumn{3}{|l|}{ Living children } \\
\hline 1 & 288 & 41.1 \\
\hline $2+$ & 412 & 58.9 \\
\hline \multicolumn{3}{|l|}{ Using Family Planning } \\
\hline No & 14 & 2 \\
\hline Yes & 686 & 98 \\
\hline \multicolumn{3}{|l|}{ Current age of respondents } \\
\hline$<20$ years & 175 & 25 \\
\hline $20-29$ years & 386 & 55.1 \\
\hline-45 years & 139 & 19.9 \\
\hline \multicolumn{3}{|l|}{ Respondent's education } \\
\hline Illiterate & 283 & 40.4 \\
\hline Primary & 215 & 30.7 \\
\hline Secondary+ & 202 & 28.9 \\
\hline \multicolumn{3}{|l|}{$\begin{array}{l}\text { Problem during } \\
\text { last pregnancy }\end{array}$} \\
\hline No & 329 & 47 \\
\hline Yes & 371 & 53 \\
\hline $\mathbf{N}$ & 700 & 100 \\
\hline
\end{tabular}

\section{Mean Duration of Breastfeeding}

In Bangladesh, women especially in rural areas generally breastfed their babies up to 30 months. It was found that the median duration of breastfeeding among the land holding families was 33.5 months. Table III shows the percentage of the respondents according to the duration of breastfeeding.
Table III. Percentage distribution of the respondents according to the duration of breastfeeding

$\begin{array}{ccc}\text { Background } & \begin{array}{c}\text { Duration of } \\ \text { breastfeeding } \\ \text { (years) }\end{array} & \begin{array}{l}\text { No. of } \\ \text { respondents }\end{array} \\ & 2 & 2>\end{array}$

\section{Age of respondents}

\begin{tabular}{|lccc|}
\hline$<20$ & 69.1 & 30.9 & 175 \\
$20-29$ & 66.1 & 33.9 & 386 \\
$30-49$ & 60.4 & 39.6 & 139 \\
\hline $\begin{array}{l}\text { Respondent's } \\
\text { education }\end{array}$ & & & \\
\hline $\begin{array}{l}\text { Illiterate } \\
\text { Primary }\end{array}$ & 66.4 & 33.6 & 283 \\
Secondary+ & 60.9 & 39.1 & 215 \\
\hline $\begin{array}{l}\text { Total } \\
\text { Mean duration }\end{array}$ & 69.8 & 30.2 & 202 \\
\hline \begin{tabular}{l} 
(months) \\
\hline
\end{tabular} & 18.31 & 36.2 & 24.66 \\
\hline
\end{tabular}

Determinants of Duration of Breastfeeding: An Application of MCA

Results of MCA: The results indicates that the proportion of variance explained by MCA is multiple R2 $=0.415$ and multiple $R=0.644$. The low value of $R 2 \neg$ may be due to some inter-correlations among the predictor variables considered here or there may be some other factors, which may affect the mean duration of breastfeeding. Of all the variables, the current age children and BMI of the respondents appear as the important determinants of duration of breastfeeding and other variables play relatively less important roles on the duration of breastfeeding.

Among the included variables, the current age children shows the strongest influence on the duration of breastfeeding. The proportion of variance in the duration of breastfeeding explained by the current age children is the highest (unadjusted value of $\square 2=$ 0.627 and adjusted value of $\square 2=0.630$ ). It is observed that the mean (adjusted) duration of breastfeeding are 20.00 months and $\mathbf{3 4 . 1 3}$ months for the children whose current age is 3 years and $3+$ years respectively.

From the results, we see that the BMI of respondents has considerable association with the duration of breastfeeding. The proportion of variance in duration of breastfeeding explained by the BMI of respondents is $\square 2=0.146$ and $\square 2=0.072$. The effect of $B M l$ of respondents has been found to be the second strongest differentials for explaining the variation on duration of breastfeeding among the included variables. The mean duration of breastfeeding is 22.27, 24.55, and 25.18 months for those women whose BMI have $<18.5$, 18.5-24.9 and 25+ respectively. 
Determinants of Duration of Breastfeeding: An Application of MCA

Results of MCA: The results indicates that the proportion of variance explained by MCA is multiple $R 2=0.415$ and multiple $R=0.644$. The low value of $R 2\urcorner$ may be due to some inter-correlations among the predictor variables considered here or there may be some other factors, which may affect the mean duration of breastfeeding. Of all the variables, the current age children and $\mathrm{BMI}$ of the respondents appear as the important determinants of duration of breastfeeding and other variables play relatively less important roles on the duration of breastfeeding.

Among the included variables, the current age children shows the strongest influence on the duration of breastfeeding. The proportion of variance in the duration of breastfeeding explained by the current age children is the highest (unadjusted value of $\square 2=$ 0.627 and adjusted value of $\square 2=0.630$ ). It is observed that the mean (adjusted) duration of breastfeeding are 20.00 months and 34.13 months for the children whose current age is 3 years and $3+$ years respectively.

From the results, we see that the BMI of respondents has considerable association with the duration of breastfeeding. The proportion of variance in duration of breastfeeding explained by the BMI of respondents is $\square 2=0.146$ and $\square 2=0.072$. The effect of BMI of respondents has been found to be the second strongest differentials for explaining the variation on duration of breastfeeding among the included variables. The mean duration of breastfeeding is $22.27,24.55$, and 25.18 months for those women whose BMI have $<18.5$, 18.5-24.9 and 25+ respectively.

The number of living children also shows a considerable association with duration of breastfeeding. The proportion of variance explained by this variable (unadjusted) is $\square 2=0.052$ and (adjusted) is $\square 2=0.082$. The mean duration of breastfeeding is 23.42 and 25.16 months for those women who have just 1 and $2+$ living children respectively.

Current usage of family planning (FP) shows weak strength in explaining variation in mean duration of breastfeeding ( $\square 2=0.021$ ), but the effect of this variable decreases after adjusting for the effect of all other predictors in the model $(\square 2=0.003)$. The mean duration of breastfeeding is higher for women who currently used FP than the women who did not use FP, but this is not remarkable.

Another variable that emerge as an important influence on duration of breastfeeding is respondent's current age. The proportion of variance explained by the respondent's current age (unadjusted) is $\square 2=0.100$ and (adjusted) is $\square 2=0.039$. The respondent's current age has been found to be the third strongest differentials for explaining the variation on duration of breastfeeding among the included variables. From the result, it is observed that the women with higher ages have lower duration of breastfeeding. The women with age $<20$ years have 0.98 months and 0.54 months higher mean (net) duration of breastfeeding than those with ages 20-29 and 30-49 years respectively.

Respondent's educational shows a considerable association with the duration of breastfeeding. The proportion of variance explained by this variable (unadjusted) is $\square 2=0.056$ and (adjusted) is $\square 2=0.015$. It is observed that the women with secondary+ level education possess the lowest duration of breastfeeding (24.25) and with primary level education the highest (24.65). The women with no education (e.g. illiterate) are the next to the level of primary level education but this is not remarkable.

The factor of problems during last pregnancy also shows a considerably less impact on mean duration of breastfeeding. The proportion of variance explained (unadjusted) by problem during last pregnancy is $\square 2=$ 0.077 and the proportion of variance explained (adjusted) by this variable is $\square 2=0.095$. It is observed that the women with problems during last pregnancy have higher (25.38) duration of breastfeeding than the women with no problem during last pregnancy (23.39).

\section{CONCLUSION AND RECOMMENDATIONS}

This study indicated that the mean duration of breastfeeding (24.66 months) for all mothers is not so very high in the slum areas of RCC. It is also seen that the current age children is closely related with the breastfeeding practices in slum areas and the most effective one among the selected factors. It showed the strongest association $(\square 2=0.627)$ with breastfeeding. The effect of the current age children remains also high even after adjusting for the effects of all other predictors in the model $(\square 2=0.63)$. Children whose ages that were $3+$ years tended to go on breastfeeding longer time (34.13 months) than the average duration, followed by children whose ages below 3 years (having duration of breastfeeding 20.00 months only). It emphasized on the optimal feeding and care of infants and young children through protecting, promoting and supporting breastfeeding so that the older infants and young children receive sufficient energy and nutrients to meet their requirements for healthy growth, developmental and activity. ${ }^{18}$ Similarly, the BMI of the respondents play a mentionable role in influencing the mean duration of breastfeeding. The physical and mental health of those who are responsible for feeding and caring for infants, and young children should be fostered by treating the malnourished according to internationally recommended guidelines. ${ }^{18}$

Therefore, the various effective policies and recommendations are to be taken to promote the breastfeeding practices in slum areas. The specific recommendations are as follows: 
i. It is important to recognize the need for programs that will encourage the initiation and continuation of the breastfeeding practices among slum dwelling mothers.

ii. Compulsory primary education law is to enforce uniformly in slum areas so that the mothers of these areas will get proper information and realize the benefits of the low cost and much greater benefits of longer duration of breast- feeding for their family, and also for their own physical and mental health.

Table IV. Mean duration of breastfeeding by some selected variables applying MCA

Explanatory Variables
Unadjusted

\section{Children's current age}

$\leq 3$ years

$3+$ years

BMI of respondents

$<18.5$

18.5-24.9

25+

Number of living children

1

2+

Using FP

No

Yes

Current age of respondents

$>20$

20-29

30-49

Respondent's education

Illiterate

Primary

Secondary+

Problem during last pregnancy

No

Yes

Grand mean

Multiple R

Multiple ------- $\mathbf{R}^{2}$
Mean

\section{Adjusted}

Mean

Correlation Ratio

$n^{2}$

$\boldsymbol{\beta}^{2}$

0.627

0.63

20.02

20

34.09

34.13

0.146

0.072

21.34

24.19

22.27

24.55

27.14

25.18

23.8

23.42

24.9

25.16

22.93

24.19

24.47

24.45

22.93

24.56

25.09

24.11

24.55

26.02

24.43

25.19

23.68

24.43

24.65

24.25

23.59

23.39

0.052

0.082

0.021

0.003

0.1

0.039

25.19

25.38

24.66

0.644

0.415
$0.056 \quad 0.015$

0.077

0.095 


\section{REFERENCES}

1. Picciano M. Nutrient Composition of Human Milk. Pediatr Clin North Am 2001; 48: 53-67

2. Mitra SN et al. Bangladesh Demographic and Health Survey (BDHS), National Institute of Population Research and Training (NIPORT), Dhaka, Bangladesh. 2004.

3. American Academy of Pediatrics. Section on Breastfeeding. Breastfeeding and the Use of Human Milk. Pediatrics 2005; 115:495-506

4. Schanler RJ. The Use of Human Milk for Pre mature Infants. Pediatr Clin North Am 2001; 48: $207-20$

5. Schanler RJ, Atkinson SA. Effects of Nutrients in Human Milk on the Recipient Premature Infant. J Mammary Gland Biol Neoplasia 1999; 4:297-307

6. Ahmed S. Practical Support for Breastfeeding Mothers. Postgrad Doctor 1997; 13:65-9

7. United Nations Children's Fund. The State of the World's Children. New York. 1991.

8. Anonymous. A Warm Chain for Breast Feeding (editorial). Lancet 1994; 344:1239-41.

9. Briend A, Wojtynaik B, Rowland MGM. Breast feeding, Nutritional State and Child Survival in Rural Bangladesh. Br Med J 1988; 296:87982

10. World Health Organization (WHO). Breastfeeding and Fertility Regulation: Current Knowledge and Program Policy Implication. Bull WHO 1983; 61:371-82

11. Alix-Dancer P. Access to health care in developing countries. In: Developing countries, society and technology. Stockholm:Royal Institute of Technology (KTH), 2003

12. Kramer $M$, et al. Promotion of Breastfeeding Intervention Trial (PROBIT): A randomized trial in the Republic of Belarus. JAMA 2001; 285:413-20

13. World Health Organization (WHO). The Optimal Duration of Exclusive Breastfeeding. Results of a WHO Systematic Review.

Geneva. 2001. 